\title{
Role of Infiltration and Saturation Excess in Rainfall-Runoff Modelling in Small Catchments
}

\author{
Luděk Strouhal, Václav David \\ Czech Technical University in Prague \\ Faculty of Civil Engineering, Department of Irrigation, Drainage and Landscape Engineering \\ e-mail: ludek.strouhal@fsv.cvut.cz,vaclav.david@fsv.cvut.cz
}

\begin{abstract}
The paper presents the essential differences in small catchment model behaviour depending on the assumed runoff procedure, i.e. infiltration or saturation excess. It suggests an appropriate model structure and a way to obtain the required boundary conditions. In order to design the flood mitigation measures in small catchments, there is a need of reliable prediction of their behaviour. Long time series of data are rather rare here and the simple models are usually not capable to reflect all the necessary variables and their distribution. However, more comprehensive models are usually very demanding with respect to input data. A model of Bykovicky stream catchment $\left(6.3 \mathrm{~km}^{2}\right)$ was built in the physically based distributed model GSSHA. Out of two years of rainfallrunoff data several events were used for model calibration. Gradually the model was changed in order to explain observed data better. First modelling outcomes suggested a significant influence of saturation excess on flood hydrographs in most of the scenarios. In order to reflect this, the model needs to contain groundwater related processes, but the data on groundwater table position was not available. Therefore a simple method how to obtain it was proposed and tested. The paper discusses the achievements of this modelling experiment.
\end{abstract}

Key words: flood protection, small catchments, rainfall-runoff modelling, infiltration excess, saturation excess

\section{Introduction}

Several reasons arose recently why to pay attention to the small catchments' hydrology. From the most pressing the mitigation of flash floods, revitalization of the landscape or the longterm droughts can be named. Especially in the context of frequently discussed climatic change, which promises to bring the sharpening of climatic and hence also hydrological extremes in the central Europe, it becomes a topical question in hydrology.

At the Department of Irrigation, Drainage and Landscape Engineering at the FCE, Czech Technical University in Prague the hydrological models have been used for rainfall-runoff analyses of small catchments for the last decade. The focus is mainly on the flood events. In the beginning empirical and conceptual models were used, but recently they are being 
replaced by physically based models, as they better describe the spatial and temporal variability of characteristics essential for the rainfall-runoff process. For the last three years a fully distributed physically based model GSSHA [1] has been tested on the data observed in the Bykovicky stream catchment.

The knowledge of flood discharges formation gained so far suggests that it is necessary to reflect variable saturation areas in the model. It requires including subsurface processes, but the lack of all necessary input data is the common obstacle in the practical use of flood mitigation design. Therefore a method designed for avoiding this particular obstacle was tested. Its assumptions, application and results discussion follows.

\section{Observed Catchment and Modelling Software}

\subsection{Bykovicky Stream Catchment, Instrumentation}

The observed part of Bykovicky stream catchment $\left(6.3 \mathrm{~km}^{2}\right)$ is situated in the Central Bohemia in the mean altitude $440 \mathrm{~m}$ asl. The Bykovicky stream is a tributary to the Divisovsky stream, whose catchment is covered [2] in 60\% with arable land, $20 \%$ with woods and in $15 \%$ with meadows, pastures and gardens. According to the national soil databases the soil layer is predominantly composed from permeable soils, in particular sandy loam, loamy sand and sand $(67 \%, 10 \%, 8 \%$ respectively).

The instrumentation of the catchment consists of two tipping-bucket rain gauges ( $300 \mathrm{~m}$ apart, one of them serves as a back-up), pressure probe in the side-pit in the regulated channel of the stream and an ultrasonic probe for water level measuring in the control object in the culvert. All the measurements are synchronised in the 10 minutes interval. During the past years the upper soil layer survey on the arable land was carried out repeatedly and once the deeper layer was analysed in order to obtain approximate soil characteristics for the subsurface model. For more details see [3].

\subsection{Basic Characteristics of the GSSHA Model}

The physically based hydrological model GSSHA was released in 2002 as a successor of a 2D rainfall-runoff Hortonian model CASC2D [4]. Currently the 9th version is available and besides the runoff caused by infiltration excess it also enables 2D saturated zone modelling including the pollutant transport and interaction with unsaturated zone and the surface.

The infiltration procedure in the model uses either simple Green \& Ampt method, its modification with soil moisture redistribution, or Richard's equation. In all three cases the unsaturated zone is described in 1D only. For the most recent work the $9^{\text {th }}$ beta version of GSSHA was used, which was supposed to enable computations with more structured than homogenous soil profile. Unfortunately the authors experienced malfunctioning multi-layer infiltration routine in this version, which had a strong effect on the model structures used and the outcomes.

Besides the infiltration and surface runoff computations the model provides routines to include interception by using an empirical two-parameter method [5] and surface detention 
using single parameter - retention depth. All the processes may be arbitrarily spatially distributed.

\section{Model Application and Flood Runoff Formation Processes}

\subsection{Hortonian Runoff, Automatic Calibration}

The model was applied for the first time in 2010, when there was only one year of observations available. The rainfall event with second highest recorded amount was selected for testing, even though the actual value was not very high - only $23.4 \mathrm{~mm}$. At that time the catchment model considered infiltration excess as the only flood formation procedure. The simulated runoff hydrograph was compared with quick response separated from the observed total hydrograph with a standard technique of linear increase of the baseflow [6].

The fit of the model was very poor. A good agreement was found only in the time of the peak and relatively good fit in its value, but the volume of the simulated hydrograph reached only one third of the observed and the length of the response was shorter in one order of magnitude. The results clearly pointed at a different form of flood formation process in this particular event. The interflow with combination of preferential flow was probably the leading process here, but these processes cannot be simulated by any catchment-scale physically based model known to the authors. For that reason it was necessary to find a rainfall-runoff event with higher precipitation amount for another testing

In August 2010 an extreme flood event was observed in the catchment. Total amount of the storm with multiple peaks was $109 \mathrm{~mm}$ during 24 hours and maximum 10-minutes intensity exceeded $40 \mathrm{~mm} /$ hour. By comparison with statistical data from nearest gauging stations in the region the 24 hours rainfall amount with 100-year return period was exceeded.

For the analysis of this event the Hortonian model without groundwater interaction was used again. In the automatic calibration only the parameters of the three most frequent soil types and land cover classes were changed. The optimisation procedure in the model is based on the combination of genetic algorithms [7]. The comparison of the model output and separated quick response of the observed hydrograph is shown in Fig. 1.

The fit of the calibrated model was still very low; Nash-Sutcliffe Efficiency (NSE) [8] reached only 0.2 . The value was affected largely by the significant difference between the hydrograph peaks caused by the most pronounced precipitation burst. In order to minimize this difference the calibration procedure forced the parameters of hydraulic conductivity, interception and surface retention into implausible values. Using the optimized set of parameters the model produced the hydrograph with very good fit of $96 \%$ in flood volume, but Fig. 1 shows that its distribution is obviously incorrect. In comparison to the simulated distribution, the highest discharge in the channel was observed as a response to the subsidiary peak of storm hyetograph. This effect can be only explained with the formation of significant saturated areas in the catchment. Also in this case the assumption of the dominant role of surface runoff was not correct and the results showed the importance of involving subsurface procedures into the model. 


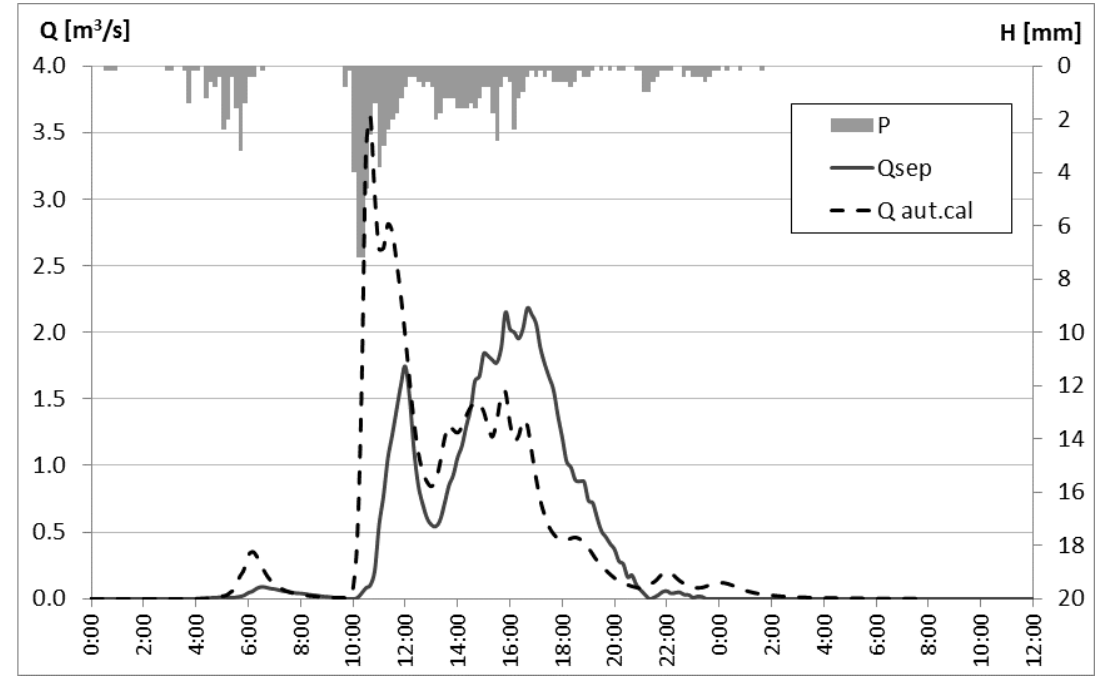

Figure 1: Simulated hydrograph from automatic calibration and separated quick response of observed flood hydrograph.

This simple model application led the authors to the suspicion regarding the adequacy of the rainfall data. The highest peak in the simulated hydrograph was unreasonably high and it proved impossible to decrease it by manipulating the model parameters within the plausible range. This fact can only be explained by an invalid assumption of homogenous distribution of the rainfall over the catchment. The total amount of the actual rainfall must have been lower than recorded with the point measurement, which was most probably not representative in this case.

\subsection{Including the Subsurface Processes into the Model Using Scarce Input Data}

The need to model the saturated areas together with the lack of any data on groundwater table in the catchment was in the background of a thought- and model experiment.

The position and gradient of the groundwater table in the thalweg determines the baseflow during the periods without precipitation. The lapse rate of the baseflow depends on the water supply rate from the upper parts of slopes. A hypothetical long period with no precipitation would lead to a complete depletion of the groundwater reservoirs (up to the level of the outlet) through the stream network. Very same drainage was modelled in order to assess the approximate position of the groundwater table with respect to the observed baseflow rates.

A homogenous soil profile was assumed, with impermeable bedrock in 10 meters depth. The starting position of the groundwater table was levelled with the terrain along the stream network and with increasing distance from the stream it was gradually (in two steps) lowered to the depth of $1 \mathrm{~m}$ below the surface. The spatially distributed set of surface soil parameters was used for the whole soil profile in order to test the behaviour of the model.

Dashed line on the Fig. 2 represents part of the simulated drainage curve. The significant peak at the beginning of the simulation is caused by emptying the stream channel and its nearest 
vicinity. After 5 days of decrease circa one and half month long period of moderate increase begins, followed by a very slight lapse of the discharge. It took approximately 1.5 year of simulation time for the model to reach the rates of the baseflow in the observed range $10-$ $20 \mathrm{l} / \mathrm{s}$ to the model, at which moment the soil profile in the upper parts of the slopes was found empty to the very bedrock. During the simulation numerous locations where exfiltration occurred were observed, especially in the points of terrain convergence or a sudden change of hydraulic conductivity. This behaviour of the model differed significantly from the real state in the watershed, but it verified the expected qualitative aspects of the model.

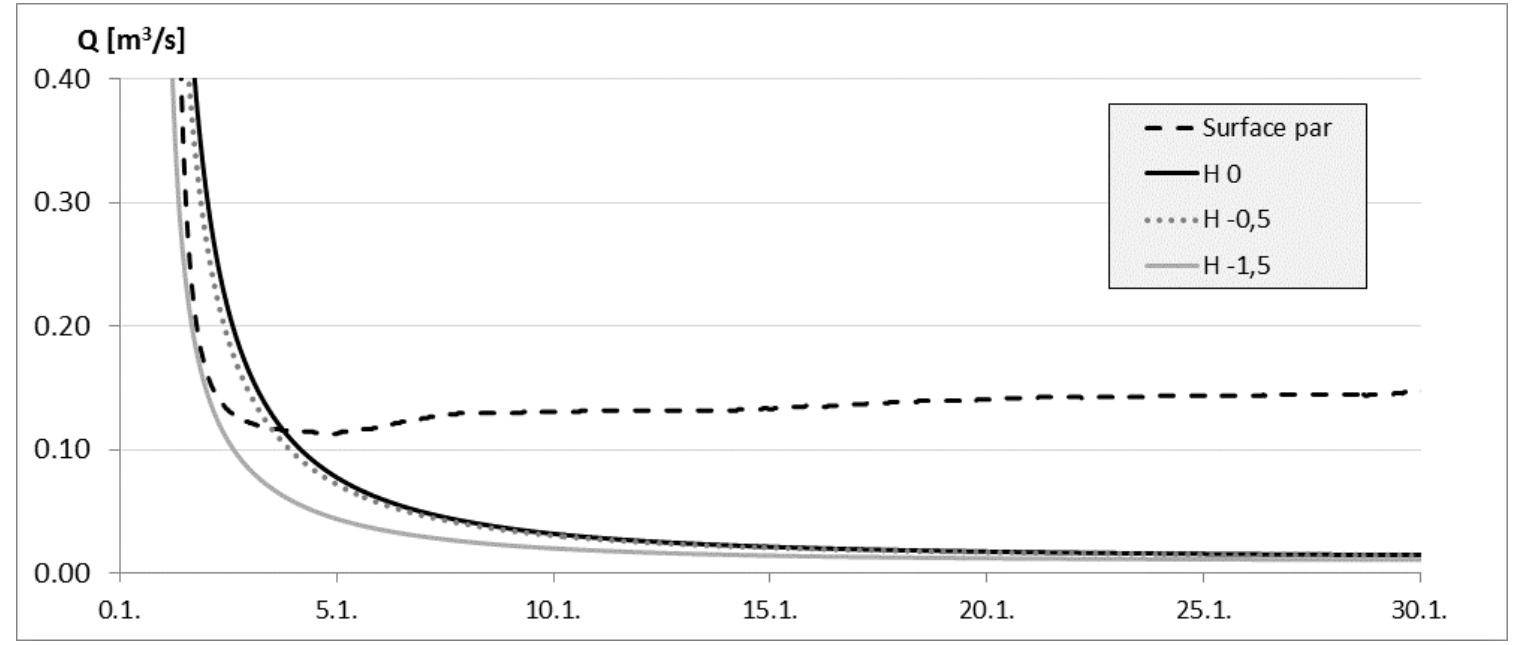

Figure 2: Drainage curves of the model with various starting levels of the GW table

As a next step real parameters for the saturated zone were set (uniformly over the catchment) and the drainage experiment was repeated. Three versions of initial level of the groundwater table were used for testing the sensitivity to this boundary condition. In the first case the groundwater table was set to the same level as in the previous test with surface parameters. Second position was set uniformly $0.5 \mathrm{~m}$ and in the last case $1.5 \mathrm{~m}$ below the surface all over the catchment. The Fig. 2 shows different behaviour of the final discharge in these versions only during the initial draining of the channel and its nearest vicinity. However, after 10 days the differences between all the curves become negligible. The simulated discharge after reaching "steady" state agreed very well with the observed flows. Across the catchment the groundwater position fluctuated within months in the range of $10 \mathrm{~cm}$ and the exfiltration appeared only sporadically. Rise of the groundwater table to the surface in these locations did not cause any noticeable change in the final depletion curve.

On one hand this experiment did not make it possible to assign unique position of the groundwater table to the observed rates of the baseflow, on the other hand it did suggest a way of including saturation process into the catchment model. Above all, it proved that the discharge in the stream is not sensitive to the position of the groundwater table higher in the catchment and that it responds to the saturated zone in the riparian area only. Therefore it was possible to choose the initial position of the groundwater table for the event modelling: almost across the whole catchment arbitrary position could be set and only within certain distance 
from the stream network it was adjusted to the level corresponding to the baseflow observed prior to the event.

\subsection{Saturation Excess Model}

A complication in stepping from the testing model to the full saturation model was that of malfunctioning multi-layered infiltration routine in GSSHA 9.0 version. Without this routine the model is only able to differentiate between unsaturated and saturated zone and to use different parameter sets for each of these. Though in order to simulate real conditions, where the decrease of hydraulic conductivity with the depth is almost the rule, it is essential to consider at least two soil layers. This need was more pronounced in this particular catchment, where the compressed soil layer in the $0.5 \mathrm{~m}$ depth was found due to the tillage mechanisms. A workaround was found using the assumptions in the end of the previous chapter. In order to simulate the lapse in hydraulic conductivity in the $0.5 \mathrm{~m}$ depth the initial groundwater table was set into this position over the catchment, only along the channels its position was derived from the drainage experiment according to the observed baseflow. Obviously it does not represent the real state, but from the point of the model in the short term simulation very similar behaviour was expected. At least the space for infiltrating water was limited, which should lead to the saturation of the surface at some point during the event.

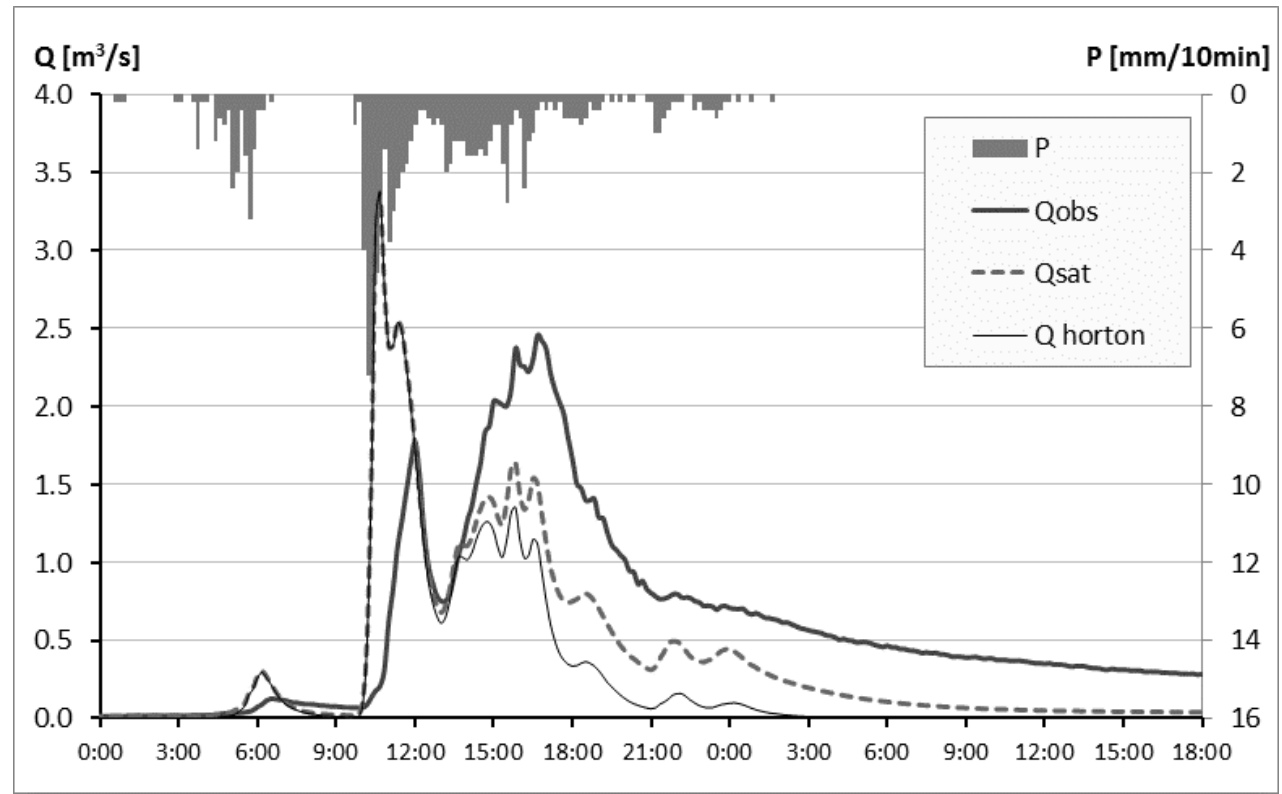

Figure 3: Full observed hydrograph compared with simulations of the Hortonian and saturation excess model

Fig. 3 shows the results of the final simulation using the saturation model. This time the simulated hydrograph could be compared with the full observed hydrograph as the model also included subsurface processes. Although the new NSE reached only 0.18, there was an improvement comparing to the Hortonian model, which produced negative NSE -0.25 being evaluated against the full hydrograph without the quick response separation. The effect of the 
first simulated peak on the value of NSE as well as the suspicion on the false assumption of the uniformly distributed rainfall were already discussed and suggest different aspects for evaluating the model than mere use of NSE. One of them can be the volume and its distribution of the simulated hydrograph. In the saturation model an increase from $43 \%$ to $63 \%$ of the total observed volume was registered. Its distribution around the false highest peak did not change as the infiltration storage of the upper soil layer was not filled yet, but significant improvement was simulated in the area of the second peak of the hydrograph and its falling limb. Moreover, the questionable procedure of quick response separation did not have to be used in the saturation model.

\section{Conclusion}

Starting with small rainfall-runoff events modelling to the extreme events recorded in the Bykovicky stream catchment other processes than Hortonian overland flow proved to be essential for the discharge formation. Most attention was paid to the saturation excess influence. The modelling experiment of catchment discharging or soil profile drainage was tested with the aim of determining the position of the groundwater table. Though it did not prove to be generally applicable for the real groundwater table localisation, with a special configuration of the model it can partially compensate for the drawbacks of the model and can be used for surface saturation modelling. Residual deviations of the model from the observations may occur partially due to the interflow and preferential flow, which is at the moment practically impossible to model in catchment-scale physical models. A part of the error may also be caused by the limitations of the modelling software, which is currently not capable of running multilayer infiltration routine. In present configuration when the shallow groundwater table substitutes the less permeable horizon, it introduces less permeable soil parameters into the upper horizon as it rises to the surface. However, in real situation the infiltrated water stays in more permeable upper horizon and can reach the channel much faster. For the next use the drainage method needs to be tested jointly with the multilayer infiltration model, which is still blocked due to the software limitations. As a next step an agricultural drainage system influence is planned for evaluation as well.

\section{Acknowledgements}

The presented work was supported by the national project COST LD11031 'Flood Characteristics of Small Catchments' and the grant from the CTU student competition fund OHK1-097/10 'Adaptation of the Water Management to the Climate Change'.

\section{References}

[1] DOWNER C., OGDEN F.L. (2004). GSSHA: A model for simulating diverse streamflow generation processes. Journal of Hydrologic Engineering. 9(3), p. 161-174

[2] ČERNOCHOVÁ K. (2011). Hydrologic assessment of Divišovský stream catchment with use of GSSHA model. (In Czech). Bachelor thesis. Prague: Czech Technical University in Prague.

[3] DAVID V. et al. (2008). Flood Risk and its Control in Small and Medium Catchments. (In Czech). Partial report of research and development project. Prague: FCE CTU in Prague. 
[4] DOWNER C., OGDEN F.L. (2002). GSSHA User's manual, Gridded Surface and Subsurface Analysis. ERDC Technical Report. Vicksburg: Engineer Research and Development Center.

[5] GRAY D.M. (1970). Handbook on the principles of hydrology. National Research Council of Canada, Water Information Center Inc., Water Research Building, Manhasset Isle, Port Washington, NY.

[6] McCUEN R.H. (1997). Hydrologic Analysis and Design. Prentice-Hall.

[7] DUAN Q.Y., GUPTA V.K. \& SOROOSHIAN S. (1993). Shuffled Complex Evolution Approach for Effective and Efficient Global Minimization. Journal of optimizatiion theory and applications. Vol. 76, No. 3, p. 501-521

[8] NASH J.E., SUTCLIFFE J.V. (1970). River Flow Forecasting Through Conceptual Models Part I - A discussion of Principles. Journal of Hydrology. Vol. 10, Issue 3, p. 282-290. 